\title{
Mental health care still a minefield at the front
}

$\mathrm{R}$ ecent Canadian military investments in mental health care are starting to yield dividends but providing that care at the battlefront still requires some "flying by the seat of your pants," according to a military mental health expert.

Among the challenges of providing "forward psychiatry" (psychiatric treatment at the front) is finding a balance between protecting a patient from further trauma and returning him to work as soon as possible, Major Dr. Alexandra Heber, clinical director of mental health services at the Canadian Forces Operational Trauma and Stress Support Centre told a special session on military mental health held at the Ottawa Hospital in Ontario on Feb. 23.

Following a 2002 report criticizing the military's handling of soldiers with post-traumatic stress disorder (PTSD), the Canadian Forces initiated a variety of measures to improve the accessibility and quality of its mental health system, and reduce the stigma of mental disorder among its members (www.forces.gc.ca /health-sante/ps/dh-sd/spr-rps-eng.asp).

Those efforts have included strengthening confidentiality and career protection for military members seeking mental health care, expanding the number of mental health professionals employed by the military, developing enhanced pre- and post-deployment screening for mental health problems and instigating mental health awareness and education as part of routine training for soldiers at various stages in their careers.

The military is beginning to see the fruits of that labour, Heber said.

In 2002, the median delay in seeking care among military members with deployment-related PTSD symptoms was 5.5 years. In comparison, more than half of those military members who reported symptoms of PTSD or depression in 2008 were already receiving care at the time of post-deployment screening, which typically occurs about five months after personnel return home.

Additional data from one garrison showed that about one-third of personnel returning from tours in Afghanistan sought mental health care within a year.

Canadian Forces members now hold "largely forward-thinking attitudes towards mental health care," according to a 2010 report on the military's suicide prevention efforts. That's a marked shift from the "distressingly common belief" among military members and leadership in 2002 that "those diagnosed with

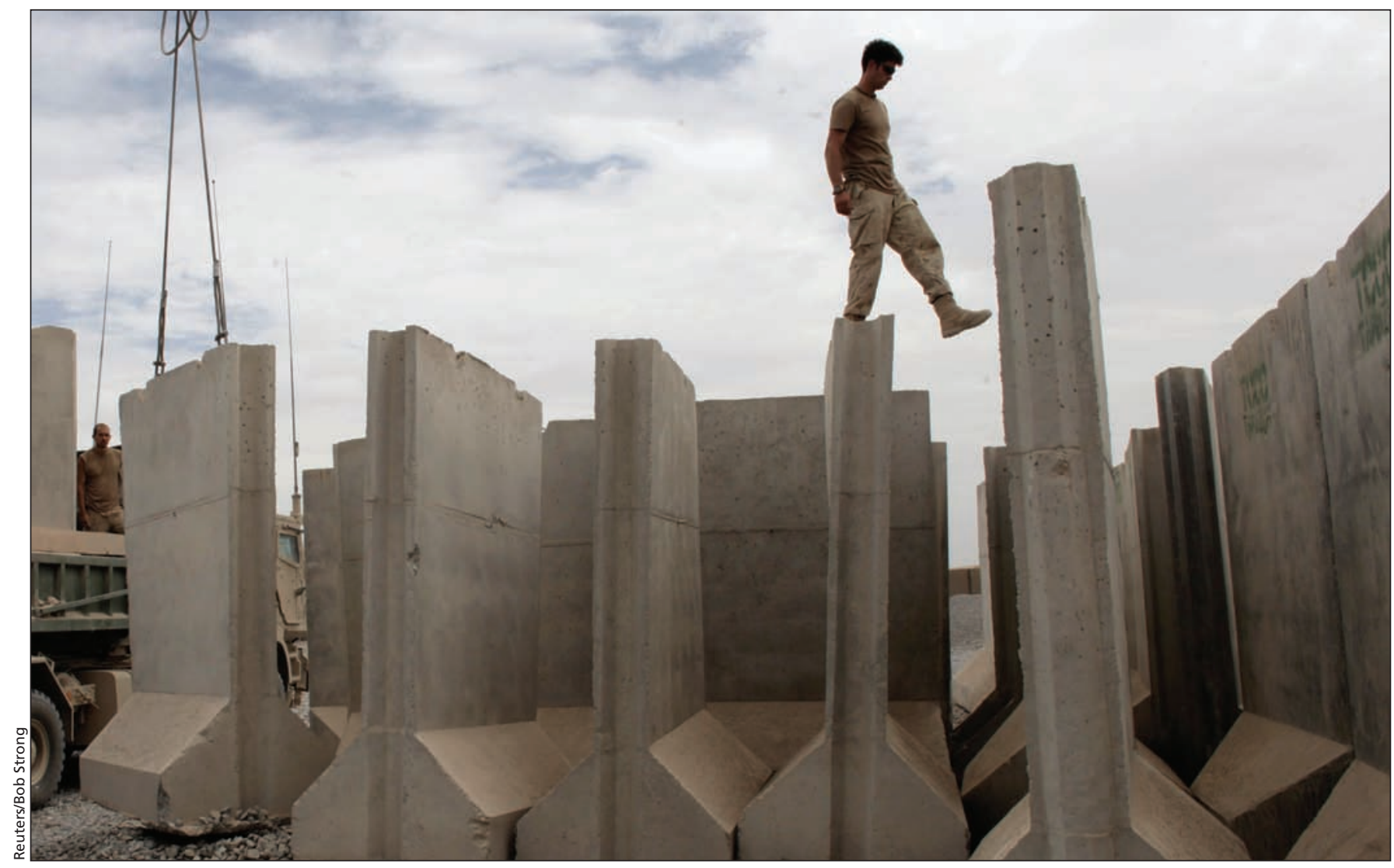

A Canadian soldier walks atop concrete security walls at a combat outpost near the village of Salavat, in the Panjway district of Afghanistan. 
PTSD were 'fakers,' 'malingers' or simply 'poor soldiers"' (www.ombudsman .forces.gc.ca/rep-rap/sr-rs/pts-ssp/rep-rap -01-eng.asp\#findings).

Consideration of a soldier's dignity and standing in the eyes of peers and military superiors are critical when delivering mental health care in a war zone, Heber said. "A big challenge in theatre is that everyone has a weapon on them. If you're concerned someone may be suicidal, everyone will know when and why you've taken their weapon away because you're supposed to have it on you at all times. That's a dilemma you'd never encounter at home."

Many nuances of delivering mental health care at the front have had to be relearned or modified during Canada's Afghanistan mission, Heber said. "I don't think we've had full mental health teams with psychiatry in a war zone since the Korean War some 50 or 60 years ago."

Forward psychiatry was pioneered by the French during World War I, after it was noticed soldiers who were removed too far behind lines or repatriated for treatment of shell shock were unlikely to return to battle.

Heber witnessed a similar trend when she began working in the Canadian Forces mental health services several years ago. "We were seeing a lot of people who had been in Rwanda, Bosnia or Somalia. At the time, some had been symptomatic for 10 years or more, if you can believe it."

It was then-common practice to give soldiers a six-month sick leave in which "we thought they'd get their therapy and get better," Heber explained. "It actually didn't work out that way. We now work very hard to keep people at work, even if it's in a more limited or modified role."

The dual mission to help patients and conserve manpower sometimes involves employing more "aggressive" treatment, particularly with regard to drugs, than might be used back home.

Treating PTSD symptoms such as shaking, for example, might not be a priority outside of a war zone, but at the front Heber would start a patient on propranolol - a drug used to treat performance anxiety among violinists and "increase the dose as tolerated fairly quickly."

"You don't want a soldier stigmatized. If he's walking around shaking, people will notice him and he'll start feeling terrible," she explained.

Mental health professionals now also involve military leaders in delivering early care for soldiers experiencing combat stress, Heber said. "We learned in the war zone our most effective medical intervention was to educate and support the chain of command to help these people first off, and only call us in if symptoms didn't resolve in a day or two. How a soldier is treated in his unit and by his buddies and leadership is more important at that point than medical treatment and most of them will recover." — Lauren Vogel, CMAJ

CMAJ 2011. DOI:10.1503/cmaj.109-3826 